\title{
Counting carbon in the Amazon
}

\section{If the next climate treaty tackles deforestation, tropical nations will need to monitor the biomass of their forests. One ecologist has worked out a way to do that from the sky, finds Jeff Tollefson.}

G reg Asner peers out an open window, taking stock of the jungle as the single-engine prop plane chugs over a pair of scarlet macaws gliding among the treetops 120 metres below. The Peruvian Amazon stretches in all directions, painted in countless shades of green, accented here and there by patches of purple, pink and yellow. Occasionally, naked white trunks rise amid the leaves, a reminder that even the rainforest has deciduous tendencies.

Forty-five minutes into the flight, Asner spots his quarry: narrow red trails, barely visible, then a fallen tree in the middle of an otherwise intact canopy. The cause isn't immediately clear to the untrained eye, but Asner knows all too well. "When trees die in the tropics, they don't just fall over," he says as the plane passes over more downed trees, a road, then a small clearing that contains stacked logs and a bulldozer. It is a legal concession, authorized by the Peruvian

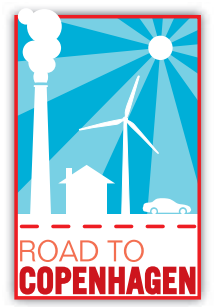

government to extract just three species of hardwood trees. As the plane veers away from the clearing, Asner gives his verdict. "The biomass levels are going to be a lot lower here," he says, "but it really is low-impact logging compared with the mayhem of Brazil."

As a tropical ecologist with the Carnegie Institution for Science's global ecology department in Stanford, California, Asner has developed a keen ability to interpret the rainforest from great heights. Frequently operating with oxygen masks at high altitude, his team uses a powerful laser system to map trees and calculate the biomass of the forest. Satellites extend his view across the tropics, and he has developed automated software that can track annual changes in forest cover and calculate the biomass of the vegetation. The system can even spot small logging operations like the one he just passed, which escape detection in most satellite studies.

The fully integrated system is designed to measure the 
amount of carbon locked up in forests and to track changes over time - an exercise that may become a crucial foundation of the new climate treaty that global leaders are hoping to sign at the United Nations Climate Change Conference in Copenhagen this December. Tropical deforestation accounts for up to $20 \%$ of the carbon dioxide emitted by humanity each year and there is broad agreement on the need to include a forest-protection element in the new treaty. This component - known as REDD, for Reducing Emissions from Deforestation and Forest Degradation - would allow developed nations to meet their required emissions-reduction targets in part by paying tropical countries to preserve their forests, which keeps carbon in trees and out of the atmosphere.

But first, tropical nations must determine how much carbon is in the forest, a notoriously difficult task. A leading researcher on remote sensing in the tropics, Asner is out to prove that developing countries can quickly and cheaply perform their own analyses, then move on to long-term carbon monitoring. He has come to Peru to demonstrate the technology and he will present the results of this proof-ofconcept test at a REDD meeting he is planning to coincide with the negotiations in Copenhagen. Success in Peru, he hopes, will bolster efforts to include a strong forest carbon component in the agreement.

The European Union last year called for a halving of deforestation by 2020, a goal that has since picked up political momentum. Estimates range widely, but reaching that target could mean pumping some US $\$ 20$ billion into tropical countries each year, according to the Union of Concerned Scientists in Cambridge, Massachusetts. Venture capitalists see profits in forest carbon and have approached Asner with business offers. Instead he has licensed his technology, dubbed CLASLite, for Carnegie Landsat Analysis System Lite, and is providing it for free to governments and others. Starting in Latin America, his team is training scientists, officials and advocacy groups on how to use the software. He likes to say that he is putting himself and other scientists out of business by injecting a decade's worth of work into the public sphere.

All this effort in testing and training has meant devoting less time to academic research, but Asner says that his work on REDD has been nothing short of rejuvenating. "This is more fun than anything I've ever done as a scientist," he says. "These forests are really special. We need to get these people some cash and protect them."

\section{Sweeping the forest}

For Asner's crew in Peru, work starts early each morning. Today, a three-man team heads to a small airport in the southeastern part of the country before sunrise in an effort to get as much mapping done as possible before the jungle pumps enough water into the air to form midday clouds. Ty Kennedy-Bowdoin runs the Light Detection and Ranging system, or LIDAR, which sweeps a laser back and forth, blasting the forest with 70,000 laser pulses per second. A sensor continuously records the signals as they bounce off leaves, branches and other objects. These data enable the researchers to calculate the height, structure and density of the forest, and they use this information to determine how much biomass it holds.

Beside Kennedy-Bowdoin in the plane is James Jacobson,

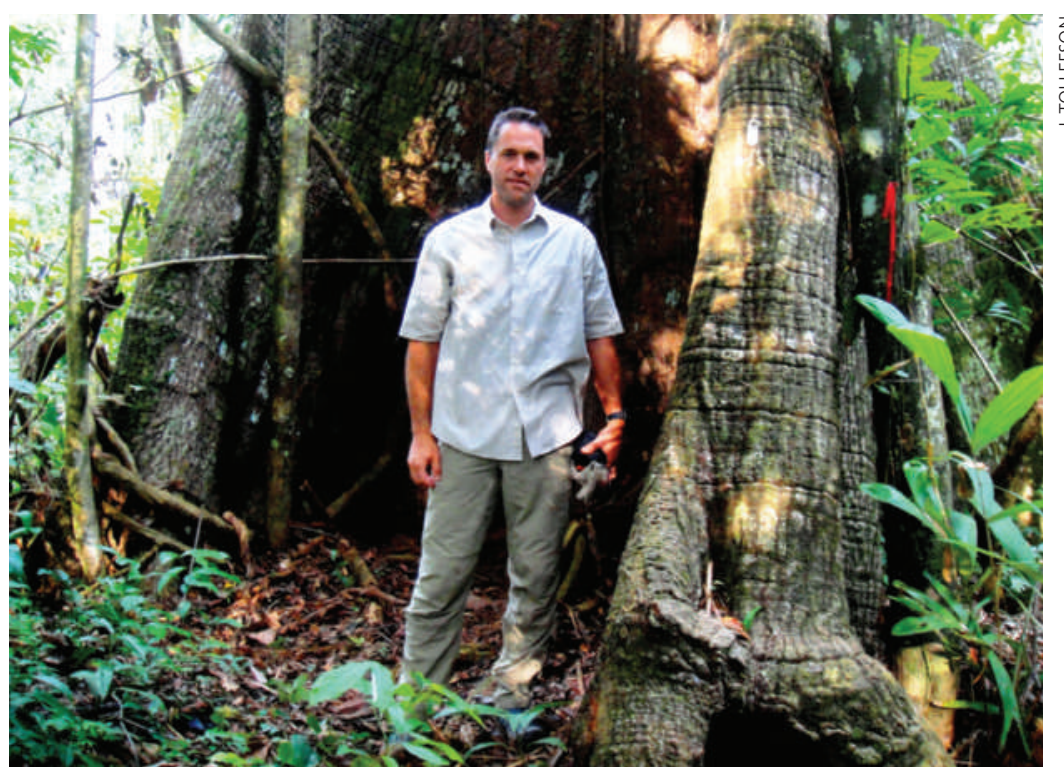

Greg Asner is trying to help tropical countries keep their forests intact.

who monitors a hyperspectral imager that takes pictures using frequencies of light that range from the visible into the infrared. The spectral data are used mostly for research on forest biodiversity, although they can also be combined with the LIDAR data to create full-colour three-dimensional images. On this particular flight, Kennedy-Bowdoin eyes a computer monitor to confirm that the LIDAR readings are coming in properly as the plane slowly flies back and forth. But after several passes small clouds move in and block the laser. The plane returns to the airport, allowing the crew to
"The forces against deforestation are getting stronger, but the forces driving deforestation are getting stronger too." - George Powell

(1)
break for lunch before another run in the evening, once the clouds have dissipated.

Back on the ground, Asner and a few colleagues head off into the jungle. They drive west along the InterOceanic Highway that crosses South America, then take a small logging road into the rainforest. It's dark by the time they finish a final hike to the Tambopata River and hop on a motor boat for a 45-minute ride to a research station upstream; a spotter scans the river with a flashlight, occasionally directing the boat away from logs.

There they meet up with a second team that is organizing ground plots. After waking up to the sound of monkeys in the morning, the team divides into several groups and heads out into the field; they have to finish around 30 plots before moving on to other locations throughout a study area larger than Denmark.

At one of the field plots, strings stretch 30 metres out from a pole in multiple directions. In the middle, the researchers are busy running a tape measure around any tree bigger than 10 centimetres in diameter; in some places, they sample down to 5 centimetres. A laser finder gauges the height of each tree. With those data, Asner's team can calculate biomass for every tree in the plot, and those numbers are then plugged into equations to calculate the biomass for the patch of forest.

With a smile, Asner explains that this cumbersome process is currently the gold standard for biomass assessment. "People running tape measures around trees. This is 
what we've got to get away from," he says.

Asner does this by taking to the skies. The laser pulses of the airborne LIDAR provide the main biomass estimate for large swathes of forest. The ground plots help his team to interpret and verify the laser readings for different types of vegetation (see 'How to measure a forest'). Old-growth forest filled with hardwood, for example, contains much more biomass per hectare than do regions dominated by bamboo. The CLASLite system then adds the numbers up according to vegetation type and extent to produce an estimate for the entire forest. Initial results suggest that these remote-sensing techniques are just as accurate as plots, Asner says, but they allow a small team to cover vast territories in a short time.

"Greg has already demonstrated that a tiny group of people can deploy this system over the scale of an entire country; the preliminary activities in Peru make that clear," says Chris Field, Asner's boss at Carnegie who is co-chair of the impacts, adaptation and vulnerability working group for the Intergovernmental Panel on Climate Change (IPCC). "I think it's an incredibly important development in science, and I'm a tremendous fan of his ability to make these things happen."

Sandra Brown, a leading biomass expert at the non-profit organization Winrock International in Arlington, Virginia, acknowledges that plot-based assessments, although reliable, simply cannot cover as much territory as remotesensing methods. She also says that published biomass estimates vary wildly for a given region, highlighting the need to establish baselines across the tropics that everybody can agree on. Stopping short of a blanket endorsement, she says that she is encouraged by Asner's initial results and is anxious to see the process in action. "I think it's got a lot of promise," she says.

The current project in Peru costs around $\$ 430,000$, half of which was funded by the Norwegian government through a grant to the environmental group WWF. That equates to roughly 10 cents per hectare, with about half of the money spent on fuel and the plane, but Asner expects the costs to fall over time. Countries could elect to develop their own

LIDAR capacity, he says, or hire one of the more than

100 commercial operators around the world. For perspective, Asner estimates that he could map all of the world's tropical forests with his system for roughly $\$ 15$ million-\$20 million.

\section{Map quest}

Asner owes his interest in forests to a hurricane named Iniki, which swept the Hawaiian islands in 1992. Asner was stationed there with the US Navy at the time, and he wound up surveying forest damage on Kaua'i after taking a job with the Nature Conservancy the following year. Asner recalls being "enthralled with the beauty, the wildness, the enormous hurricane damage and the onslaught of invasive species". His first scientific paper focused on the carnage caused by Iniki, but it was his work with invasive species that made him realize he was missing something as he struggled to assess the forest: maps.

His quest for spatial data took him to the University of
"People running tape measures around trees. This is what we've got to get away from." - Greg Asner Colorado at Boulder for graduate work in ecology, biogeochemistry and remote sensing, and then all over the world. For Asner, now 41, it is hard to separate research from the rest of his life. His wife, Robin Martin, is a postdoc in his lab and they spend most of their time together in the field. And for the first test of the new biomass system earlier this year, he chose to measure Hawai' $i$, where he lives part time.

In that analysis, Asner's group identified roughly 48 million tonnes of above-ground biomass across the island. That is about $40 \%$ lower than the results the researchers obtained from published data and a simple protocol established by the IPCC, which would be the probable starting point for any country that is setting up a carbon-assessment programme. Asner's method has cut the calculated uncertainty in half and he says his system is accurate enough to meet criteria set out by the IPCC for advanced biomass monitoring (G. P. Asner Environ. Res. Lett. 4, 034009; 2009). Satisfied with his results in Hawaii, Asner set his sights on Peru, where he has worked for several years on estimating biomass and other research.

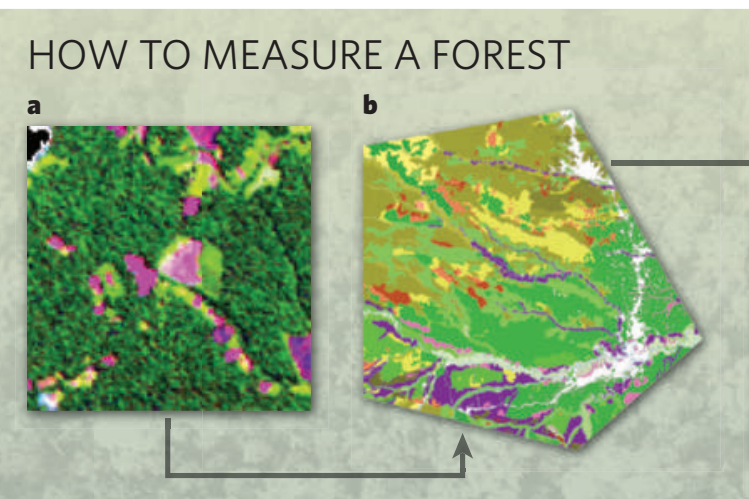

Greg Asner's automated software, called CLASLite, analyses raw satellite imagery to produce a current picture of forest cover and disturbance (a). These data are then lined up against existing maps that categorize different types of vegetation (b). Laser-based instruments called LIDARs are flown on planes to measure the density of biomass in each vegetation type (c). A small number of ground plots (d)
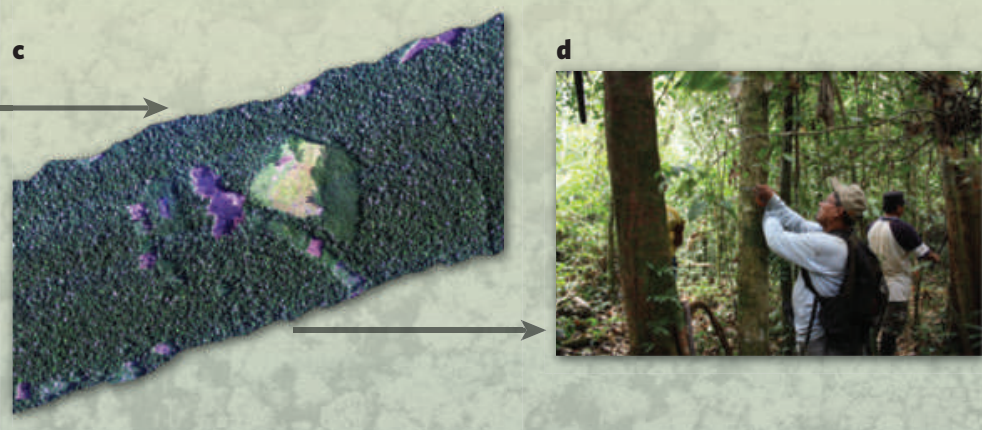

help to calibrate and validate the LIDAR estimates. CLASLite then applies the biomass estimates across the entire study area to produce an overall biomass estimate, which can then yield the total carbon content of the vegetation. After an initial assessment, CLASLite can monitor biomass levels on an annual basis; countries could deploy LIDAR occasionally to assess areas of particular interest. 


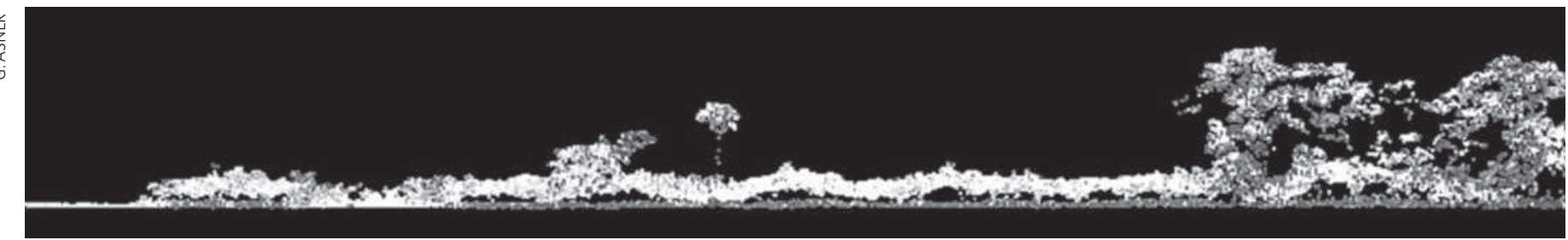

Laser-based measurements assess forest biomass.

The Carnegie crew began its project in Peru with a CLASLite analysis of NASA Landsat images around Puerto Maldonado, which is tucked into a corner of the southeastern Peruvian Amazon near Bolivia and Brazil (see map, opposite). Puerto is a poor frontier town of nearly 30,000 inhabitants, with more descending from the Andes along the newly paved InterOceanic Highway every day in pursuit of riches provided by logging, agriculture and, most recently, gold mining. Rainforest is nowhere to be seen in this dusty Amazonian town, but thousands of motorcycles buzz about, many powering a local variation on the rickshaw taxi.

The region around Puerto Maldonado, however, is one of the most biodiverse locations on the planet and a hub of deforestation. This makes it a prime target for Asner, who says that the government has shown it is ready to

\section{protect its forests.}

In 2008, Peru created its first environment ministry. Vanessa Vereau, former vice-minister, says that Peru is working to build up regional governance even as it increases federal enforcement capacity by putting more police on the ground.

It is also installing federal prosecutors in rural areas to ensure that everybody - government officials, companies and individuals - face real consequences when they break environmental laws. Success is by no means assured, but the government has not even tried to impose such order until now, says Vereau. Peru has also established its own version of a REDD programme by creating monetary incentives for indigenous communities that agree to protect their forests instead of cutting them down.

Unlike Brazil, where squatters take advantage of undesignated territories, Peru has designated its land in the Amazon as parks and conservation areas as well as concessions for timber, Brazil nuts and other resources. Along the roads outside Puerto, however, are mostly fallowed fields in place of former rainforest, illustrating how poverty and poor soils combine to create endless pressure to clear land. Although the new federal actions are encouraging, governance remains weak and the fundamental frontier economics have not changed, says George Powell, a wildlife biologist with the WWF who is based in Peru and has become one of Asner's partners on the project.

"The forces against deforestation are getting stronger, but the forces driving deforestation are getting stronger too," Powell says one evening after the team returns from the airport to a small hotel that serves as base camp for Asner's team and for local bosses who are directing work on the InterOceanic Highway. Even as the Peruvian government paves the way for bigger trucks to haul more resources out of the jungle, he says, Asner is blazing a trail that could make carbon payments a reality and help tilt the balance in favour of standing forests. "Most people are still talking about what remote sensing can and can't do," says Powell. "Greg is already down the road putting it in the hands of users. He's three steps ahead."

Seen from the vantage of a satellite, the deforestation around Puerto extends like fish bones, following roads in long, crossing lines. These are the obvious clear cuts, where forest has been chopped down for farming. Asner's CLASLite analysis also picks up countless blips of smallscale logging far out into the forest.

The best Landsat images for analysing vegetation have a 30-metre resolution, which is roughly the size of a large tree crown. This misses small roads and hardwood logging operations that substantially reduce biomass levels deep within the forest and precede widespread deforestation. In 2005, Asner published a paper on the Brazilian Amazon in Science illustrating how probabilistic algorithms could be used to sniff out the hidden spectral signals of selective - and often illegal - logging (G. P. Asner Science 310, 480-482; 2005).

That study also roughly doubled previous estimates of the amount of forest affected by human activities, while increasing the estimated greenhouse-gas emissions from the Amazon by up to $25 \%$ compared with deforestation alone. It also made a name for Asner and helped him to attract financial backing from the MacArthur Foundation, the Gordon and Betty Moore Foundation and other organizations. In total, they have given him more than $\$ 11$ million to support his biomass and deforestation work, as well as other biodiversity research.

Some of that funding has gone into producing and testing a new version of CLASLite, which is designed to make it easy to conduct a biomass assessment and to set up a monitoring programme. Import a publicly available satellite image and CLASLite will correct for atmospheric conditions at the time the image was taken, then analyse the spectrum of each pixel. Vegetation that photosynthesizes has a different spectral signal from dead trees, rocks or soil. A 'Monte Carlo' analysis then produces a range of possible combinations that converge on the most likely explanation for the data. For instance, bare soil is rarely exposed to the sky in a 


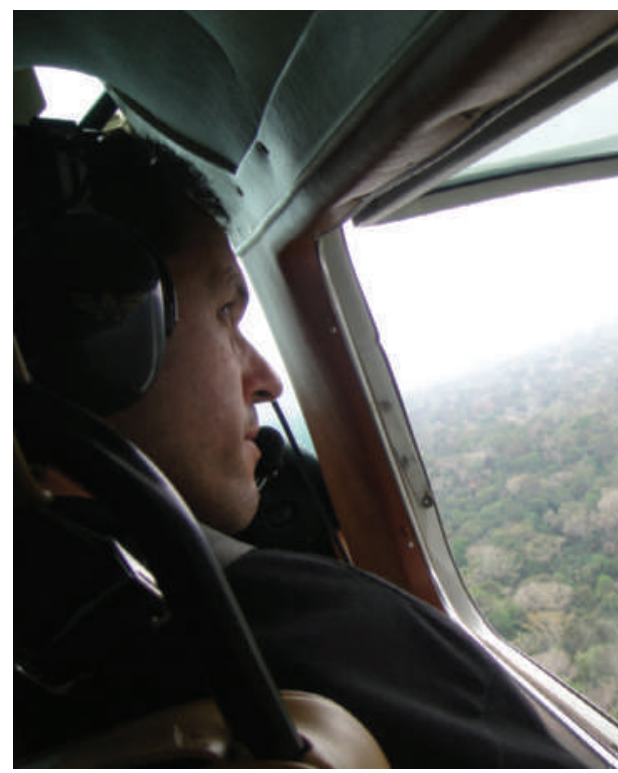

The CLASLite software developed by Greg Asner reveals where new forest destruction (green and yellow specks) extends into a protected area (red).

fast-growing rainforest; if CLASLite picks up even a tiny red signal associated with the region's iron-rich soils, and that red colour extends in a line through multiple pixels, the most likely explanation would be a road.

In addition to analysing the satellite data, the software automatically pulls in existing vegetation maps and suggests locations for both aerial measurements and ground plots. In other words, the program helps to plan an integrated biomass analysis similar to the one that Asner is conducting around Puerto. "We were trying to figure out what users want, and then we finally realized they want everything, and they want to be able to hit a button," Asner

super-giant! That's a 300-year-old tree," he says. "These are just amazing organisms!”

Asner's work could soon have a much broader impact thanks to an agreement he recently reached with Google.org on a forest-monitoring application that would be freely available on the web. That partnership, which could be announced as early as next month, could further reduce start-up costs for tropical countries by providing them with processing power and easy access to freely available satellite data from agencies such as NASA and the Brazilian Space Agency. Asner isn't allowed to talk about it, and Google officials won't go into detail except to say that they are building a rainforest-monitoring platform and that Asner's CLASLite software will be part of the package.

Dan Nepstad, a tropical ecologist at the Woods Hole Research Center in Falmouth, Massachusetts, predicts that the remote-sensing community is on the verge of a major transformation that will open the doors to high-quality forest monitoring on a global scale. He cites progress on many fronts but says that Asner has shown a particular knack for making his science relevant and useful to policymakers, particularly those in tropical countries. "There has to be trust in the forest-monitoring data, and these nations have to see them as their own," he says. "There's this face-to-face collaboration that is really critical."

Having spent most of his time over the past two years working to deploy his vision of REDD, Asner is now planning to shift into other projects. He is already working on an instrument for his biodiversity and biomass research that combines a more powerful LIDAR with sensors that capture reflected light in 440 frequencies. He is also taking another look at the issue of selective logging.

Asner recently completed his first, as yet unpublished, analysis of logging across the tropics and found that smallsays. "There's 10 years wrapped up in this little widget. That's super-secret sauce."

As of this week, Asner has trained more than 240 people in six countries on the software, including several Peruvian government officials. For Peru, the project represents an opportunity to build up its scientific capacity and perhaps even leapfrog Brazil, which currently has the world's most advanced forest-monitoring programme. Deforestation is responsible for a large - and unknown - fraction of emissions in Peru, and the country is banking on REDD as a new development aid to buttress conservation efforts while reducing carbon emissions.

"It's a new issue for us, but there is a real political will to protect the forests," says Vereau. She sees the current partnership with Asner as a pilot project that could go national "if it has strong results".

Asner acknowledges the tremendous challenges ahead. He must convince not only the Peruvian government that the system works but also the broader scientific community and ultimately, perhaps, policy-makers who are debating how to restructure the global economy around carbon. But if he has any lingering doubts, they are smothered by his boundless enthusiasm. Flying over the Amazon, Asner can't help but marvel at the sights below. "Wow, there's another

"There has to be trust in the forestmonitoring data."

- Dan Nepstad 